\title{
Structural Analysis of Heschl's Gyrus in Schizophrenia Patients with Auditory Hallucinations
}

\author{
Daniela Hubl $^{\mathrm{a}}$ Vérène Dougoud-Chauvin ${ }^{\mathrm{a}} \quad$ Markus Zeller $^{\mathrm{a}} \quad$ Andrea Federspiel $^{\mathrm{a}}$ \\ Chris Boesch $^{b}$ Werner Strik ${ }^{a}$ Thomas Dierks ${ }^{a}$ Thomas Koenig ${ }^{a}$ \\ a University Hospital of Psychiatry and ${ }^{\mathrm{b}}$ Department of Magnetic Resonance Spectroscopy and Methodology, \\ Department of Clinical Research, University of Bern, Bern, Switzerland
}

\section{Key Words}

Auditory verbal hallucinations $\cdot$ Schizophrenia $\cdot$

Heschl's gyrus • Asymmetry • Magnetic resonance imaging • Volumetry $\cdot$ Plasticity

\begin{abstract}
Background/Aims: Heschl's gyrus (HG) is functionally involved in the genesis of auditory verbal hallucinations (AVH). This dysfunction seems to be structurally facilitated. The aim of the study was to analyze macrostructural features of HG in a group of patients reporting $\mathrm{AVH}$ who demonstrated white matter diffusion tensor imaging abnormalities reported previously. Methods: 3-D anatomical MR scans were obtained (patients with and without history of $\mathrm{AVH}$, controls). HG was delineated by manual segmentation. Cortical folding, absolute and relative volumes, laterality were analyzed. Results: According to the literature, in the collapsed group of patients, the normal left-greater-than-right laterality of HG was attenuated. We found a trend towards a higher number of duplicated $\mathrm{HG}$ in hallucinating patients. We also found a bigger volume of $\mathrm{HG}$ in the right hemisphere in hallucinating patients. This effect was caused by gray and white matter increase. Conclusions: This is the first study on manual volumetry of HG in a group of schizophrenia patients with AVH
\end{abstract}

compared to patients without AVH. In a previous analysis of the diffusion tensor imaging data of the here presented sample, we found higher directionality of the arcuate fasciculus in patients with $\mathrm{AVH}$, facilitating abnormal co-activation in the auditory cortices in the hallucinating brain. As these abnormal activations are frequent in hallucinating patients, the here described volume increase of HG might be interpreted as compensatory plastic adaptations of the contralateral regions. We suggest that this volume increase of $\mathrm{HG}$ is caused by the symptomatology and not by the underlying disorder of schizophrenia.

Copyright $\odot 2009$ S. Karger AG, Basel

\section{Introduction}

Hallucinations are perceptions without sensory stimulus [1]. In schizophrenia, they are most frequently auditoryverbal hallucinations $(\mathrm{AVH})$ comprising fully formed sentences, often in the form of comments or commands [2]. This preponderance of AVH is consistent with the hypothesis that language and psychosis have a common evolutionary origin [3].

In the last two decades, an atlas of the functional neuroanatomy of AVH has emerged based on structural and

\section{KARGER}

Fax +4161306 1234 E-Mail karger@karger.ch www.karger.com (c) 2009 S. Karger AG, Basel

0302-282X/10/0611-0001\$26.00/0

Accessible online at:

www.karger.com/nps
Daniela Hubl, MD

University Hospital of Clinical Psychiatry

Bolligenstrasse 111, CH-3000 Bern 60 (Switzerland)

Tel. +41 31930 9522, Fax +41319309404

E-Mail hubl@puk.unibe.ch 
functional imaging studies: the occurrence of hallucinations is associated with activations in the language system that are predominantly located in the left hemisphere and include frontal motor-speech areas and temporal semantic areas [4-6]. Importantly, activation of the primary auditory cortex (PAC) was also reported [4]. This was interpreted as a simultaneous representation of the acoustic properties of a voice heard during a verbal thought, adding the attribute of 'being alien', and interfering with the normally felt quality of being 'self-generated'. This activation seems to be a constituting factor of AVH mechanism, not only an epiphenomenon [7], since cortical responsivity to external stimulation of the PAC is reduced during AVH. Diffusion tensor imaging data [8] suggests that these dysfunctions might be caused by a structural facilitation of the white matter (WM) paths connecting frontal with temporal auditory and language areas. Further, deep brain structures and the limbic system are involved with the cortical network, contributing to the affective and mnestic features of AVH [9].

One of the most investigated brain regions in schizophrenia - especially concerning the investigation of $\mathrm{AVH}$ - is the left temporal lobe, containing - among others - primary and secondary auditory areas. Most literature focuses on volume of the planum temporale, unfortunately sparing the PAC. Although several studies have investigated the morphology of these structures, the resulting body of literature is conspicuously inconsistent, due to a potentially large part of methodological differences [10-12]. Most studies computed correlations between the volume of interest and the momentary presence of AVH at measurement time, disregarding the patients' history of hallucinations. Few studies have followed a symptom-guided approach or focused on specific anatomical changes associated with AVH [for review, see 9]. Some studies have reported a negative correlation between the severity of the AVH and the volume of the superior temporal gyrus [13-17]. However, results are not unequivocal, since some authors have found the correlation in the anterior part [13], others in the transversal part [14] or in the total volume [15-17]. Explicitly negative results have also been published [18-21]. Studies that patients classified according to their history of hallucinations (instead of correlating with severity) have not supported these previous findings of a reduced volume in AVH [20, 21].

Only few studies focused on volume of Heschl's gyrus (HG), hosting the PAC. For HG, however, in longitudinal studies initially normal left-sided volumes were found decreasing along with functional measures during the course of the disorder. This was interpreted as an excitotoxic phenomenon $[22,23]$. These studies indicate a progressive loss of left temporal volume as a marker for schizophrenia rather than a specific finding in AVH.

From a previous analysis of the diffusion tensor imaging data of the here presented sample, we know that the directionality of the WM as measured with diffusion tensor imaging in the temporal lobe differs between patients with and without AVH and healthy controls [8]. The interesting and meanwhile well-replicated $[24,25]$ observation was that there was an increase of directionality of fiber-tracks connecting HG with other brain regions selective for patients that frequently experienced $\mathrm{AVH}$. This has been interpreted as a potential mechanism leading to abnormal co-activation in the auditory cortices in the hallucinating brain. This effect was initially reported to be left-sided. However, also the right hemisphere seems to be involved $[8,24,25]$. As repeatedly smaller HG in the course of the disease have been reported in the left hemisphere $[23,26]$, the hemisphere known to be mainly affected in schizophrenia, we hypothesized a compensatory, contralateral increase of volume of the HG that is specific to patients prone to hallucinations independent of the diagnosis of schizophrenia. This hypothesis is based on the fact of higher directionality in the arcuate fasciculus in hallucinating patients that might facilitate abnormal co-activation of the auditory cortex associated with plastic structural adaptations of the involved regions. This hypothesis is justified by studies that have shown an increase of gray matter (GM) and WM after frequent functional activation of the respective region. Accordingly, in the present volumetric MR study, total volumes, GM and WM volumes of HG in frequently hallucinating patients, in patients that reportedly had never experienced hallucinations and healthy controls were compared for the first time.

\section{Methods}

Diffusion tensor imaging data from the same subjects have already been published [8]. This paper presents volumetric data. Patient recruitment and scanning methods will thus be described only cursorily, whereas all information specific to this study will be described in detail (for all online supplementary material, see www.karger.com/doi/10.1159/000258637).

\section{Subjects}

Thirteen acute schizophrenic patients (ICD-10) with frequent AVH $(\mathrm{H}), 13$ acute schizophrenic patients who never perceived $\mathrm{AVH}(\mathrm{N})$ and 13 healthy control subjects $(\mathrm{C})$ were investigated. In $\mathrm{N}, 2$ male subjects later were excluded due to ambiguous anatom- 
ical proportions (large interrater disagreements). Groups were matched for sex and age; all subjects were right-handed. All but 2 patients received typical or atypical antipsychotic treatment in conventional dosages. The investigation was conducted in accordance with the Declaration of Helsinki and approved by the local ethics committee. Before the investigation began, all patients and healthy control subjects gave their written informed consent to participate in the study.

\section{Assessment of Psychopathology}

Each patient was carefully assigned to one of the two groups, $\mathrm{H}$ or N. N included only patients who had never experienced AVH or pseudo-hallucinations, neither at the time of this investigation nor at any time in their previous history. In $\mathrm{H}$, all patients were prone to hallucinations and experienced verbal AVH at the time of the present hospitalization as well as during all the prior exacerbations of their disease. Additionally, psychopathology and severity was assessed by application of the Positive and Negative Symptom Scale (PANSS) [27] and Clinical Global Impression Scale (CGI) [28].

\section{MR Methods}

A 1.5 T Signa MR-system (General Electric Medical Systems, Milwaukee, Version 5.8, equipped with 'echospeed' gradients of $22 \mathrm{mT} / \mathrm{m}$ ) was used for the investigations. Individual whole brain $3-\mathrm{D}$ anatomy was measured with a $3-\mathrm{D}$ gradient echo sequence, providing 124 axial slices with $1.2 \mathrm{~mm}$ thickness, $240 \times 240 \mathrm{~mm}$ field of view $(\mathrm{FOV})$, and $256 \times 128$ pixel resolution. Further scanning parameters were as follows: $22 \mathrm{~ms}$ repetition time (TR), $8 \mathrm{~ms}$ echo time (TE), and a flip angle of $45^{\circ}$. Total 3 -D scan time was $9.04 \mathrm{~min}$.

\section{Segmentation}

Anatomical $\mathrm{T}_{1}$-weighted 3-D high-resolution data have been rotated into the AC-PC line as well as in the other two axes to correct for potential tilts without normalization or transformation. Each individual anatomical data set was automatically segmented in a first step at the GM-cerebrospinal fluid boundary (fig. 1b) and in a second step at the GM-WM boundary (fig. 1c) using BrainVoayagerQX ${ }^{\circledR}$ standard procedure. Thus, we were able to measure the total brain volume, the WM volume and, by subtracting the WM volume from the total brain volume, the GM volume (fig. 1d). In addition, the volume of HG was manually segmented. The original voxel size of $0.94 \times 1.88 \times 1.20 \mathrm{~mm}^{3}$ was interpolated to a voxel size of $1 \times 1 \times 1 \mathrm{~mm}^{3}$ as given default size for any anatomical BrainVoyagerQX ${ }^{\circledR}$ analysis. All segmentations were carried out in the BrainVoyagerQX ${ }^{\circledR}$ software using the segmentation tool.

\section{Definition of $H G$}

$\mathrm{HG}$ is located in the superior part of the temporal lobe, namely in the first transverse temporal gyrus $[29,30]$. HG segmentations commonly follow the early definition of HG given by Pfeifer [31]. Specifically, we accepted landmarks to identify HG in the anatomical data (fig. 2) as published by Yousry [32]. Borders of HG were set according to Kwon [33].

A very important point was to determine whether HG was single or double. When multiple gyri were present, PAC is confined to the anterior portion of the gyrus. Thus, tissue located behind the first Heschl's sulcus were not assigned to the volume

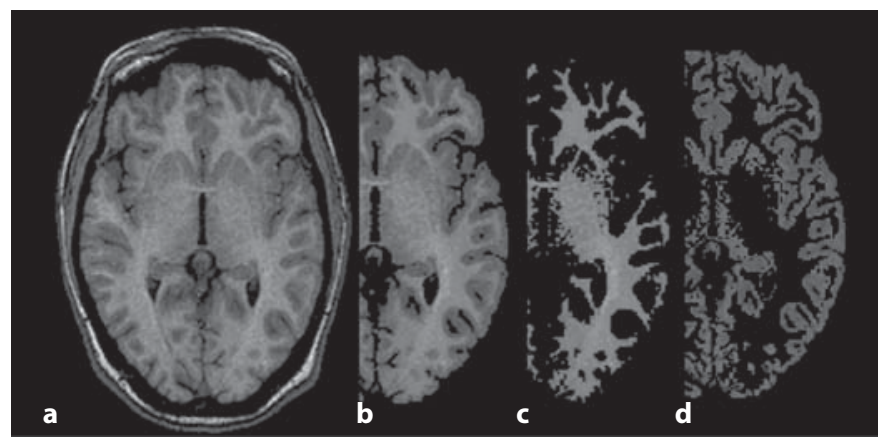

Fig. 1. Segmentation of 3-D structural MRI data. a Anatomical $\mathrm{T}_{1}$-weighted 3-D high-resolution data have been rotated into the AC-PC line without normalization or transformation. b Segmentation of the individual anatomical data at the boundary between the GM-cerebrospinal fluid. c Segmentation of the individual anatomical data at the GM-WM boundary. Thus, total brain volume and the WM volume could be determined. d GM volume was computed subtracting the WM volume from the total brain volume. These segmentations were computed automatically using BrainVoyagerQX ${ }^{\circledR}$.

of the HG but assumed to be part of planum temporale. In HG, the presence of a common stem indicates a single gyrus. Only when a sulcus intermedius deepens throughout its length to cleave the gyrus in two is the deep long sulcus called Heschl's sulcus and two HG are considered to be present.

All volumes were segmented by two independent raters who were blind to the diagnoses. Segmentations were performed by each of the raters and the average volume sizes across raters were further analyzed. In 2 cases of low interrater accordance (value $[($ rater $1-$ rater 2$) /($ rater $1+$ rater 2$)]<0.2)$, ambiguous anatomy was assumed, and the subjects were excluded from further analysis.

For further analysis, the number of voxels of the respective volume was counted automatically with in-house programming using Matlab ${ }^{\circledR}$ routines. Absolute $(\mathrm{ml})$ and relative (absolute partial volume/total brain volume of the respective hemisphere $\times$ $100)$ volumes were determined $[11,32]$.

\section{Correction of the Number-of-HG Bias}

In the case of two HG, only the volume of the first gyrus was assigned to volume of HG, because the volume of the second was assumed to belong functionally to the PT. We found that across groups, subjects with one HG had consistently larger HG volumes than subjects with two HG. The number of HG was therefore considered as a confounding variable. Its effect was corrected for by linear regression across all subjects, and separately for each hemisphere.

\section{Statistical Analysis}

ANOVAs and t tests were calculated for the demographic and psychopathological data and absolute and relative volumetric data using Statistica ${ }^{\circledR}$ software. Where specific and directed hypotheses were available, one-tailed t tests were applied. Bonferroni correction was computed where necessary. Results were ac- 


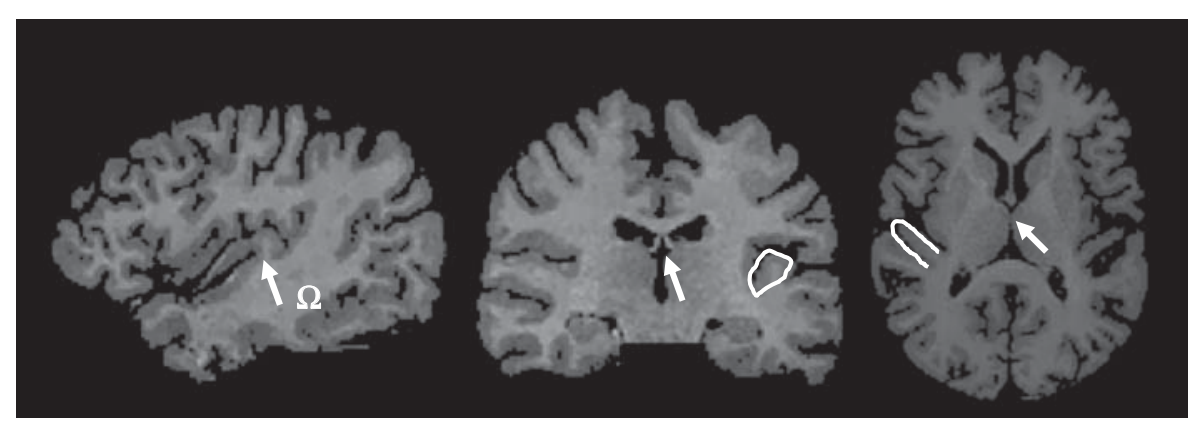

Fig. 2. Segmentation of HG: HG was visually identified in the 3-D anatomical data according to the particular landmarks in the sagittal, coronal and axial slices. In the sagittal view (left) the $\Omega$ identifies HG, in the coronal slices (middle), HG was best seen in the slice where the fornices form a tent, close to the slice where the two branches of the fornix unify. In the axial slice, HG could be best identified at the height of the adhesio interthalamica. (For optimal visualization of the respective structures, MRI slices of one subject have been chosen.) cepted to be significant at a $5 \%$ level. The following comparisons were made:

(1) In a very first step, we tested for volume differences between the hemispheres to investigate the reliability of our data in comparison with literature.

(2) Then the specific hypothesis of bigger volumes in AVH was tested separately for the left and right hemisphere for total volume as well as for the GM and WM volume in the group of patients with $\mathrm{AVH}(\mathrm{H})$ versus the group of subjects without $\mathrm{AVH}$ (including $\mathrm{C}$ and $\mathrm{N}$ ).

(3) To support the hypotheses that eventual differences were associated with the symptom but not with the disorder, we tested the two groups differing for the symptom but not for the diagnosis (equal for diagnosis, different for symptom: $\mathrm{H}$ vs. $\mathrm{N}$ ) - where we expected differences - and the two groups differing for the diagnosis but not for the symptom (equal for symptom, different for diagnosis: C vs. N) where no differences were expected.

\section{Results}

\section{Subjects}

Subjects did not differ in age (C [mean $\pm \mathrm{SD}]: 33 \pm$ $9 y, H: 33 \pm 8 y, N: 31 \pm 9 y ; p=0.82, F(2,36)=0.20)$, and sex (5 females), or duration of the disease (patients only; $\mathrm{H}: 8 \pm 7 \mathrm{y}, \mathrm{N}: 9 \pm 7 \mathrm{y} ; \mathrm{p}=0.76, \mathrm{t}(24)=0.31)$. Positive PANSS (H: $23 \pm 6, \mathrm{~N}: 18 \pm 7$ ) was significantly higher in $\mathrm{H}$ compared to $\mathrm{N}(\mathrm{p}=0.03, \mathrm{t}(24)=2.27)$ due to higher values in the hallucinations item. There was no difference between the patient groups for any of the other scores (CGI [H: $5 \pm 1, \mathrm{~N}: 5 \pm 1](\mathrm{p}=1.00, \mathrm{t}(24)=0.00)$ or PANSS total score $[\mathrm{H} 88 \pm 15, \mathrm{~N}: 80 \pm 18](\mathrm{p}=0.25$, $\mathrm{t}(24)=-1.18)$ or PANSS-negative score [H: $21 \pm 5, \mathrm{~N}$ : $22 \pm 6](\mathrm{p}=0.47, \mathrm{t}(24)=0.73))$
Total Brain Volume

Mean total brain volume $(\mathrm{n}=39)$ was $0.987 \pm 0.1081$, with 53\% GM (left hemisphere [LH]: 50\%; right hemisphere [RH]: 50\%) and 47\% WM (LH: 48\%; RH: 52\%) (table 1).

A repeated measurement ANOVA of the factor 'group' $(\mathrm{C}, \mathrm{H}, \mathrm{N})$ and the dependent variables 'hemisphere' ( $\mathrm{LH}$, RH) and 'tissue' (WM, GM) indicated significant differences for hemisphere $(\mathrm{p}<0.001, \mathrm{~F}(2,36)=59.13)$ and tissue $(\mathrm{p}<0.001, \mathrm{~F}(2,36)=32.42)$. There were no significant group effects.

Post-hoc testing identified significantly greater GM volume compared to WM volume $(\mathrm{p}<0.001, \mathrm{t}(38)=$ 5.76). $\mathrm{RH}$ volume was significantly greater than $\mathrm{LH}$ volume $(\mathrm{p}<0.001$, t $(38)=7.85)$.

\section{Macro-Anatomy of HG}

$\mathrm{HG}$ is described as the first transverse temporal gyrus. It is found to be a single but sometimes as a double (or even triple) gyrus, too. We found higher variability of $\mathrm{HG}$ in the RH. Often it was more difficult to define the borders of HG in RH due to greater variance in morphology. In the $\mathrm{LH}$, we found 32 single and 5 double $\mathrm{HG}(\mathrm{C}: 1, \mathrm{H}$ : 2, N: 2) and in the RH, 23 single and 14 double HG (C: 4, $\mathrm{H}: 7, \mathrm{~N}: 3)$. Across all subject groups, double $\mathrm{HG}$ was found more often in the RH than in $\mathrm{LH}\left(\chi^{2}=4.3, \mathrm{p}=\right.$ 0.04). Within groups, this remained a trend $\left(\chi^{2}=2.78\right.$, $\mathrm{p}=0.09)$ in $\mathrm{H}$, without reaching significance in $\mathrm{C}\left(\chi^{2}=\right.$ $1.8, \mathrm{p}=0.18)$ or $\mathrm{N}\left(\chi^{2}=0.2, \mathrm{p}=0.65\right)$.

\section{Volume of HG: Hemispheric Differences}

Left-greater-than-right asymmetry for the total HG volume was found as expected in $\mathrm{C}(\mathrm{t}(12)=-2.78, \mathrm{p}=$ 
Table 1. Total brain volumes for patients with hallucinations, patients without hallucinations and controls

\begin{tabular}{|c|c|c|c|c|c|c|}
\hline & \multicolumn{2}{|l|}{$\mathrm{C}$} & \multicolumn{2}{|l|}{$\mathrm{H}$} & \multicolumn{2}{|l|}{$\mathrm{N}$} \\
\hline \multicolumn{7}{|l|}{ Absolute, 1} \\
\hline Total brain volume & \multicolumn{2}{|l|}{$0.998(0.109)$} & \multicolumn{2}{|c|}{$0.998(0.118)$} & \multicolumn{2}{|c|}{$0.966(0.096)$} \\
\hline GM volume & \multicolumn{2}{|l|}{$0.523(0.389)$} & \multicolumn{2}{|c|}{$0.532(0.067)$} & \multicolumn{2}{|c|}{$0.466(0.053)$} \\
\hline \multirow[t]{2}{*}{ WM volume } & \multicolumn{2}{|l|}{$0.475(0.768)$} & \multicolumn{2}{|c|}{$0.505(0.062)$} & \multicolumn{2}{|c|}{$0.461(0.064)$} \\
\hline & $\mathrm{L}$ & $\mathrm{R}$ & $\mathrm{L}$ & $\mathrm{R}$ & $\mathrm{L}$ & $\mathrm{R}$ \\
\hline Total brain volume & $0.49(0.05)$ & $0.50(0.05)$ & $0.49(0.06)$ & $0.51(0.06)$ & $0.48(0.05)$ & $0.49(0.05)$ \\
\hline GM volume & $0.26(0.02)$ & $0.26(0.02)$ & $0.27(0.04)$ & $0.26(0.03)$ & $0.26(0.03)$ & $0.25(0.03)$ \\
\hline WM volume & $0.23(0.03)$ & $0.24(0.04)$ & $0.22(0.03)$ & $0.24(0.04)$ & $0.22(0.03)$ & $0.24(0.03)$ \\
\hline
\end{tabular}

Mean (SD) total brain volumes with GM and WM sub-volumes for the three groups. $\mathrm{GM}=\mathrm{Gray}$ matter; $\mathrm{WM}=$ white matter; $\mathrm{L}=$ left; $\mathrm{R}=$ right; $\mathrm{C}=$ controls; $\mathrm{H}$ = patients with $\mathrm{AVH} ; \mathrm{N}$ = patients without $\mathrm{AVH}$.

Table 2. Mean volumes of HG (SD) with GM and WM sub-volumes for patients with hallucinations, patients without hallucinations and controls and left-right comparison

\begin{tabular}{|c|c|c|c|c|c|c|c|c|c|c|c|c|}
\hline & \multicolumn{4}{|l|}{$\mathrm{C}$} & \multicolumn{4}{|l|}{$\mathrm{N}$} & \multicolumn{4}{|l|}{$\mathrm{H}$} \\
\hline & $\mathrm{L}$ & $\mathrm{R}$ & $\mathrm{t}(12)$ & $\mathrm{p}$ & $\mathrm{L}$ & $\mathrm{R}$ & $\mathrm{t}(10)$ & $\mathrm{p}$ & $\mathrm{L}$ & $\mathrm{R}$ & $\mathrm{t}(12)$ & $\mathrm{p}$ \\
\hline \multicolumn{13}{|l|}{ Absolute, $\mathrm{mm}^{3}$} \\
\hline Total HG & $2,448(672)$ & $1,780(678)$ & 2.78 & 0.02 & $2,244(554)$ & $1,836(627)$ & 2.01 & 0.07 & $2,412(708)$ & $2,298(600)$ & 0.52 & 0.61 \\
\hline GM of HG & $1,902(499)$ & $1,177(400)$ & 4.02 & $<0.01$ & 1,715 (459) & $1,101(397)$ & 4.53 & $<0.01$ & $1,926(469)$ & $1,426(377)$ & 3.05 & 0.01 \\
\hline WM of HG & $545(221)$ & $603(362)$ & -0.54 & 0.60 & $529(141)$ & $734(356)$ & -1.79 & 0.10 & $485(235)$ & $871(394)$ & -3.89 & $<0.01$ \\
\hline \multicolumn{13}{|l|}{ Relative } \\
\hline Total HG & $0.49(0.12)$ & $0.35(0.12)$ & 2.81 & 0.02 & $0.49(0.12)$ & $0.38(0.12)$ & 2.33 & 0.04 & $0.49(0.13)$ & $0.46(0.10)$ & 0.75 & 0.47 \\
\hline GM of HG & $0.38(0.08)$ & $0.23(0.79)$ & 4.05 & $<0.01$ & $0.37(0.10)$ & $0.23(0.08)$ & 4.80 & $<0.001$ & $0.39(0.09)$ & $0.28(0.07)$ & 3.34 & 0.01 \\
\hline WM of $\mathrm{HG}$ & $0.11(0.04)$ & $0.12(0.06)$ & -0.25 & 0.81 & $0.12(0.03)$ & $0.15(0.07)$ & -1.62 & 0.14 & $0.10(0.04)$ & $0.17(0.07)$ & -3.66 & $<0.01$ \\
\hline
\end{tabular}

Left-greater-than-right asymmetry for the total $\mathrm{HG}$ volume was found as expected in $\mathrm{C}$, but not in $\mathrm{N}$ and $\mathrm{H}$.

$\mathrm{GM}=$ Gray matter; $\mathrm{WM}=$ white matter; $\mathrm{HG}=$ Heschl gyrus; $\mathrm{L}=$ left $\mathrm{R}=$ right; $\mathrm{C}=$ controls; $\mathrm{H}=$ patients with $\mathrm{AVH} ; \mathrm{N}=$ patients without $\mathrm{AVH}$. One-tailed t tests, Bonferroni correction for testing two hemispheres.

0.017), but not in either patient group $\mathrm{N}$ or H. For both sides, GM was bigger than WM (absolute values: R: $\mathrm{GM}=1,242 \pm 405 \mathrm{~mm}^{3}, \mathrm{WM}=736 \pm 379 \mathrm{~mm}^{3} ; \mathrm{L}:$ $\mathrm{GM}=1,855 \pm 482 \mathrm{~mm}^{3}, \mathrm{WM}=519 \pm 202 \mathrm{~mm}^{3}$; relative values: $\mathrm{R}: \mathrm{GM}=0.251 \pm 0.079, \mathrm{WM}=0.146 \pm 0.069$; $\mathrm{L}$ : $\mathrm{GM}=0.383(0.088), \mathrm{WM}=0.107 \pm 0.039)$ with $\mathrm{p}<0.01$ (table 2; fig. 3).

\section{Symptom Dependence of HG Volume}

Bigger volume of the $\mathrm{HG}$ was observed in the right hemisphere (total volume: $\mathrm{t}(35)=-2.27, \mathrm{p}=0.03$, GM of HG: $\mathrm{t}(35)=-2.13, \mathrm{p}=0.04)$ in subjects with $\operatorname{AVH}(\mathrm{H})$ compared to subjects without AVH (C and N) (table 3).

To support that these differences were associated with the symptom of AVH and not with the disorder, we com- pared C versus $\mathrm{N}$ (groups are equal for symptom but different for diagnosis) and did not find differences. Whereas in the comparison of $\mathrm{H}$ versus $\mathrm{N}$ (groups are equal for diagnosis but differ in symptomatology) volumes were bigger in the RH for each volume (total HG: $\mathrm{t}(24)=2.39$, $\mathrm{p}=0.03$, GM: t $(24)=1.99, \mathrm{p}=0.05$, WM: $\mathrm{t}(24)=2.15$, $\mathrm{p}=0.04)($ table 4$)$.

\section{Discussion}

The functional anatomy of AVH includes auditory cortex and language-related brain regions. The present study examined morphological differences in the primary auditory regions that were chosen by virtue of 
Table 3. Comparison for symptom dependence mean volumes of HG (SD) with GM and WM sub-volumes for subjects with symptoms of $\mathrm{AVH}(\mathrm{H})$ and subjects without $\mathrm{AVH}(\mathrm{C}$ and $\mathrm{N})$ for both hemispheres

\begin{tabular}{|c|c|c|c|c|c|c|c|c|}
\hline & \multicolumn{4}{|l|}{$\mathrm{L}$} & \multicolumn{4}{|l|}{$\mathrm{R}$} \\
\hline & $\mathrm{AVH}$ & no AVH & $\mathrm{t}(12)$ & $\mathrm{p}$ & $\mathrm{AVH}$ & no AVH & $\mathrm{t}(10)$ & $\mathrm{p}$ \\
\hline \multicolumn{9}{|l|}{ Absolute, $\mathrm{mm}^{3}$} \\
\hline Total HG & $2,412(708)$ & $2,355(616)$ & 0.25 & 0.80 & $2,298(600)$ & $1,806(642)$ & 2.27 & 0.03 \\
\hline GM of HG & $1,926(496)$ & $1,816(480)$ & 0.66 & 0.52 & $1,426(377)$ & $1,142(392)$ & 2.13 & 0.04 \\
\hline WM of HG & $485(235)$ & $538(185)$ & -0.74 & 0.46 & $871(394)$ & $663(358)$ & 1.63 & 0.11 \\
\hline \multicolumn{9}{|l|}{ Relative } \\
\hline Total HG & $0.488(0.126)$ & $0.491(0.117)$ & -0.07 & 0.95 & $0.455(0.100)$ & $0.365(0.119)$ & 2.32 & 0.03 \\
\hline GM of $\mathrm{HG}$ & $0.391(0.089)$ & $0.378(0.089)$ & 0.40 & 0.69 & $0.285(0.073)$ & $0.232(0.078)$ & 2.01 & 0.05 \\
\hline WM of HG & $0.097(0.043)$ & $0.112(0.037)$ & -1.10 & 0.28 & $0.170(0.072)$ & $0.133(0.065)$ & 1.62 & 0.11 \\
\hline
\end{tabular}

Bigger volumes in symptom carriers were found in the right hemisphere for the total volume, mainly caused by an increase of GM.

$\mathrm{GM}=$ Gray matter; $\mathrm{WM}=$ white matter; $\mathrm{HG}=\mathrm{Heschl}$ gyrus; $\mathrm{L}=$ left $\mathrm{R}=$ right; $\mathrm{C}=$ controls; $\mathrm{H}=$ patients with $\mathrm{AVH} ; \mathrm{N}=$ patients without AVH. One tailed t tests, Bonferroni correction for testing two hemispheres.

Table 4. Influence of the disorder to test whether the volume increase in the right hemisphere is caused by the symptom or by the disorder

\begin{tabular}{|c|c|c|c|c|}
\hline & \multicolumn{2}{|c|}{$\begin{array}{l}\text { Equal for disorder/ } \\
\text { different for symptom }\end{array}$} & \multicolumn{2}{|c|}{$\begin{array}{l}\text { Equal for symptom/ } \\
\text { different for disorder }\end{array}$} \\
\hline & $\mathrm{t}(22)$ & $\mathrm{p}$ & $\mathrm{t}(24)$ & $\mathrm{p}$ \\
\hline \multicolumn{5}{|l|}{ Absolute, $\mathrm{mm}^{3}$} \\
\hline $\mathrm{R}$ total $\mathrm{HG}$ & 2.06 & 0.03 & 0.21 & 0.42 \\
\hline R GM of $\mathrm{HG}$ & 1.63 & 0.05 & -0.46 & 0.32 \\
\hline R WM of HG & 1.80 & 0.04 & 0.89 & 0.19 \\
\hline \multicolumn{5}{|l|}{ Relative } \\
\hline $\mathrm{R}$ total $\mathrm{HG}$ & 2.47 & 0.01 & 0.72 & 0.24 \\
\hline R GM of HG & 1.73 & 0.05 & -0.05 & 0.48 \\
\hline R WM of HG & 2.12 & 0.02 & 1.43 & 0.08 \\
\hline
\end{tabular}

In the comparison between the two groups with schizophrenia (equal for disorder but different for expression of $\mathrm{AVH}$ ), we found right hemispheric differences whereas there were no differences in the comparison between the groups with and without schizophrenia.

$\mathrm{GM}=$ Gray matter; $\mathrm{WM}=$ white matter; $\mathrm{HG}=$ Heschl gyrus; $\mathrm{L}=$ left $\mathrm{R}=$ right $\mathrm{C}=$ controls $\mathrm{H}=$ patients with $\mathrm{AVH} ; \mathrm{N}=$ patients without AVH. One-tailed t tests.

their functional role in etiopathology of AVH. Macroscopic features such as volume, laterality and cortical folding of the PAC were assessed manually in three different subject groups: hallucinating patients, patients who never experienced hallucinations, and control sub- jects. From the analysis of the diffusion tensor imaging data of the here presented sample, we know from the prior analysis of the diffusion tensor imaging data [8] that there was an increase of directionality of fibertracks connecting $\mathrm{HG}$ with other brain regions selective for patients that experienced frequent AVH. We interpreted this increase of directionality as a potential mechanism leading to the abnormal co-activation in the auditory cortices in the hallucinating brain. Thus, the pathological activation of HG would not be generated in the HG itself alone, but rather by abnormal, structurally facilitated input from other regions. In the present study, we found a volume increase in the right, but not in the left HG, supporting the hypothesis that frequent and abnormal activation might be associated with plastic structural adaptations of involved regions [33-35]. The volume increase seems to be due to increased WM and GM in hallucinating patients.

We found an increased volume of the auditory region in the RH. At first glance, this appears to be contradictory to the fact that the structural and functional alterations related to hallucinations were often found to be more pronounced on the left side. The findings, however, are not exclusively restricted to the LH since also the homologue contralateral regions are involved $[8,24,25]$. We conclude that the here described unilateral volume increase might be due to an interhemispheric compensation mechanism as known from stroke recovery $[36,37]$, which in this context can be understood as a cortical reorganization mechanism in hallucinating schizophrenia 


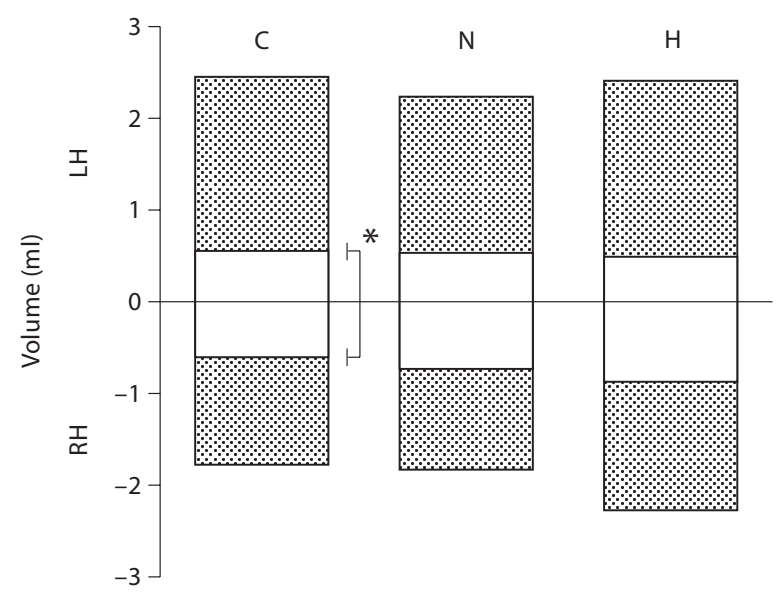

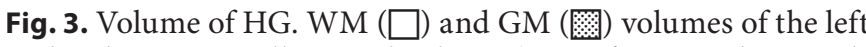
and right $\mathrm{HG}$ as well as total volume (sum of WM and GM volume) are shown. Volumes are printed separately for each study group, $C(n=13), N(n=11)$ and $H(n=13)$. Total volume was significantly larger in the $\mathrm{LH}$ compared to the $\mathrm{RH}$ in $\mathrm{C}$ but not in $\mathrm{H}$ and $\mathrm{N}$, where asymmetry was attenuated. GM was significantly larger than WM for all groups in both hemispheres. $\mathrm{C}=$ Controls, $\mathrm{H}=$ hallucinating patients, $\mathrm{N}=$ non-hallucinating patients, $\mathrm{LH}=$ left hemisphere, $\mathrm{RH}=$ right hemisphere. ${ }^{*} \mathrm{p}<0.05$.

patients [38]. Possibly the well-known and often replicated LH functional $[39,40]$ and structural deficits $[26,39$, 41] in schizophrenia-related to language-related thought disorders and hallucinations are developmental and, due to a structural vulnerability, even progressive. Compensatory plasticity effects would then be observed only in the non-affected RH homologue regions [42, 43]. However, our findings of increased $\mathrm{RH}$ volume in $\mathrm{AVH}$ might indicate a predisposition [44-46] as well as an adaptation. This was described for WM of the auditory and language system $[35,47]$. Together with the higher incidence of bifurcated $\mathrm{HG}$ in the $\mathrm{RH}$, the right-sided WM excess may also be explained by a developmental pathology of the physiological hemispheric asymmetry.

There are relatively few studies that investigated the laterality and the volume of HG in schizophrenia. Some studies focusing on HG volume in schizophrenia reported as a main finding a progressive volume reduction predominantly of the left but not of the right $\mathrm{HG}[22,23]$. The finding was also found in schizotypy [48]. However, these studies were conducted on larger groups of schizophrenic patients, not selected for the presence of halluci- nations. Further, there are also greater volumes of HG in patients with AVH reported [31] (left: $+5 \%$, right: $+8 \%$ ) indicating that $\mathrm{HG}$ volume changes might be a dynamic phenomenon and object to compensatory plasticity as well as to excitotoxic degeneration according to the individual predisposition. However, the dynamic state of the language system during pathological activation, chronicity of the process and compensatory capacities of the contralateral homologue regions are not yet fully understood.

In contrast to all these studies on the volume of HG in schizophrenia, in our study, schizophrenia patients with and without hallucinations have been compared. In the above-listed studies, a group of schizophrenia patients independent of their lifetime symptomatology have been compared with healthy controls. Thus, this effect of volume loss in the HG seems to be a kind of vulnerability marker for schizophrenia spectrum disorders more than a marker for AVH. We could not support a significant general loss of HG volume, however the descriptive values for $\mathrm{LH}$ volumes in patients for most volumes were smaller compared to $\mathrm{C}$.

In accordance with the literature - as reliability check - we found a significant left-greater-than-right laterality of the total volume of $\mathrm{HG}$ in $\mathrm{C}$, whereas this was attenuated in $\mathrm{H}$ and $\mathrm{N}$ without significant hemispheric difference. Further, GM was bigger compared to WM volume in controls and schizophrenia patients [35, 49].

One limitation of the present study is the relatively small number of subjects that were however clinically rather homogeneous. From a statistical point of view, there is probably a trade-off between increasing the number of analyzed subjects, and reducing within-group variance by more stringent inclusion criteria, and it is at the moment unclear where the optimal choice is. Increasing the number of subjects is also problematic because this method is so time-consuming that large subject groups are hardly feasible, i.e. in HG volumetry the five most high-ranking studies investigated on average 20 (range 18-22) controls and 17 (range 13-21) patients [22, 31, 32, $48,50]$. Controversial results have been published in these papers, suggesting small and susceptible results for minor methodological differences.

In the present study, a reliable method was applied, aiming at a high-end methodological approach with manual segmentation, high resolution of the $3-\mathrm{D}$ voxels in data with reported microstructural differences. We found that RH total volume of HG with contribution of WM and GM sub-volume were bigger in patients with frequent $\mathrm{AVH}$ compared to patients without $\mathrm{AVH}$ and 
healthy subjects, probably caused by a reorganization mechanism and plasticity. However, the different results between this and other studies might be due to different sub-group recruitment, using here a clear long-term symptom-led inclusion strategy.

\section{Acknowledgments}

We would like to cordially thank Thomas Zetzsche for his great help on the definition of the planum temporale borders and Pietro Ballinari for statistical support. Support by the Swiss National Science Foundation (3200-059077.99 to T.D.) is gratefully acknowledged.

\section{References}

1 Schneider K: Klinische Psychopathologie, ed 15. Stuttgart, Thieme, 2007.

2 David AS: The cognitive neuropsychiatry of auditory verbal hallucinations: an overview. Cognit Neuropsychiatry 2004;9:107-123.

- 3 Crow TJ: Is schizophrenia the price that Homo sapiens pays for language? Schizophr Res 1997;28:127-141.

-4 Dierks T, Linden DE, Jandl M, Formisano E, Goebel R, Lanfermann H, Singer W: Activation of Heschl's gyrus during auditory hallucinations. Neuron 1999;22:615-621.

5 McGuire PK, Shah GM, Murray RM: Increased blood flow in Broca's area during auditory hallucinations in schizophrenia. Lancet 1993;342:703-706.

-6 Shergill SS, Brammer MJ, Williams SC, Murray RM, McGuire PK: Mapping auditory hallucinations in schizophrenia using functional magnetic resonance imaging. Arch Gen Psychiatry 2000;57:1033-1038.

-7 Hubl D, Koenig T, Strik WK, Garcia LM, Dierks T: Competition for neuronal resources: how hallucinations make themselves heard. Br J Psychiatry 2007;190:57-62.

-8 Hubl D, Koenig T, Strik W, Federspiel A, Kreis R, Boesch C, Maier SE, Schroth G, Lovblad K, Dierks T: Pathways that make voices: white matter changes in auditory hallucinations. Arch Gen Psychiatry 2004;61: 658-668.

-9 Allen P, Laroi F, McGuire PK, Aleman A: The hallucinating brain: a review of structural and functional neuroimaging studies of hallucinations. Neurosci Biobehav Rev 2008;32:175-191.

10 Shapleske J, Rossell SL, Woodruff PW, David AS: The planum temporale: a systematic, quantitative review of its structural, functional and clinical significance. Brain Res Brain Res Rev 1999;29:26-49.

- 11 Zetzsche T, Meisenzahl EM, Preuss UW, Holder JJ, Kathmann N, Leinsinger G, Hahn $\mathrm{K}$, Hegerl U, Moller HJ: In-vivo analysis of the human planum temporale (PT): does the definition of PT borders influence the results with regard to cerebral asymmetry and correlation with handedness? Psychiatry Res 2001;107:99-115.

12 Meisenzahl EM, Zetzsche T, Preuss U, Frodl T, Leinsinger G, Moller HJ: Does the definition of borders of the planum temporale influence the results in schizophrenia? Am J Psychiatry 2002;159:1198-1200.
13 Rajarethinam RP, DeQuardo JR, Nalepa R, Tandon R: Superior temporal gyrus in schizophrenia: a volumetric magnetic resonance imaging study. Schizophr Res 2000; 41:303-312.

14 Crespo-Facorro B, Kim JJ, Chemerinski E, Magnotta V, Andreasen NC, Nopoulos P: Morphometry of the superior temporal plane in schizophrenia: relationship to clinical correlates. J Neuropsychiatry Clin Neurosci 2004;16:284-294.

15 Barta PE, Pearlson GD, Powers RE, Richards SS, Tune LE: Auditory hallucinations and smaller superior temporal gyral volume in schizophrenia. Am J Psychiatry 1990;147: 1457-1462.

16 Levitan C, Ward PB, Catts SV: Superior temporal gyral volumes and laterality correlates of auditory hallucinations in schizophrenia. Biol Psychiatry 1999;46:955-962.

17 Flaum M, O'Leary DS, Swayze VW, Miller DD, Arndt S, Andreasen NC: Symptom dimensions and brain morphology in schizophrenia and related psychotic disorders. J Psychiatr Res 1995;29:261-276.

18 DeLisi LE, Hoff AL, Neale C, Kushner M: Asymmetries in the superior temporal lobe in male and female first-episode schizophrenic patients: measures of the planum temporale and superior temporal gyrus by MRI. Schizophr Res 1994;12:19-28.

19 Cowell PE, Kostianovsky DJ, Gur RC, Turetsky BI, Gur RE: Sex differences in neuroanatomical and clinical correlations in schizophrenia. Am J Psychiatry 1996;153: 799-805.

20 Shapleske J, Rossell SL, Simmons A, David AS, Woodruff PW: Are auditory hallucinations the consequence of abnormal cerebral lateralization? A morphometric MRI study of the sylvian fissure and planum temporale. Biol Psychiatry 2001;49:685-693.

21 Havermans R, Honig A, Vuurman EF, Krabbendam L, Wilmink J, Lamers T, Verheecke CJ, Jolles J, Romme MA, van Praag HM: A controlled study of temporal lobe structure volumes and P300 responses in schizophrenic patients with persistent auditory hallucinations. Schizophr Res 1999;38:151-158.
22 Kasai K, Shenton ME, Salisbury DF, Hirayasu Y, Onitsuka T, Spencer MH, YurgelunTodd DA, Kikinis R, Jolesz FA, McCarley RW: Progressive decrease of left Heschl gyrus and planum temporale gray matter volume in first-episode schizophrenia: a longitudinal magnetic resonance imaging study. Arch Gen Psychiatry 2003;60:766-775.

23 Salisbury DF, Kuroki N, Kasai K, Shenton ME, McCarley RW: Progressive and interrelated functional and structural evidence of post-onset brain reduction in schizophrenia. Arch Gen Psychiatry 2007;64:521-529.

24 Shergill SS, Kanaan RA, Chitnis XA, O’Daly O, Jones DK, Frangou S, Williams SC, Howard RJ, Barker GJ, Murray RM, McGuire P: A diffusion tensor imaging study of fasciculi in schizophrenia. Am J Psychiatry 2007; 164:467-473.

25 Rotarska-Jagiela A: Anatomical brain connectivity and positive symptoms of schizophrenia: a diffusion tensor imaging study. Psychiatry Res 2009 (in press)

26 Golestani N, Pallier C: Anatomical correlates of foreign speech sound production. Cereb Cortex 2007;17:929-934.

27 Van Praag H, Kempermann G, Gage FH: Neural consequences of environmental enrichment. Nat Rev Neurosci 2000;1:191-198.

28 Schneider P, Scherg M, Dosch HG, Specht HJ, Gutschalk A, Rupp A: Morphology of Heschl's gyrus reflects enhanced activation in the auditory cortex of musicians. Nat Neurosci 2002;5:688-694.

29 Kay SR, Fiszbein A, Opler LA: The positive and negative syndrome scale (PANSS) for schizophrenia. Schizophr Bull 1987;13:261276.

30 National Institute for Mental Health. 12 CGI. Clinical Global Impressions; in Guy W, Bonato R (eds): Manual for the ECDEU Assessment Battery, ed 2 rev. Maryland, Chevy Chase, 1970.

31 Pfeifer RA: Myelogenetisch-anatomische Untersuchungen über das Kortikale Ende der Hörleitung. Leipzig, Teubner, 1920.

32 Yousry TA: Heschl's gyrus. Int J Neuroradiol 1997;3:2-12.

- 33 Kwon JS, McCarley RW, Hirayasu Y, Anderson JE, Fischer IA, Kikinis R, Jolesz FA, Shenton ME: Left planum temporale volume reduction in schizophrenia. Arch Gen Psychiatry 1999;56:142-148 
\34 Hirayasu Y, McCarley RW, Salisbury DF, Tanaka S, Kwon JS, Frumin M, Snyderman D, Yurgelun-Todd D, Kikinis R, Jolesz FA, Shenton ME: Planum temporale and Heschl gyrus volume reduction in schizophrenia: a magnetic resonance imaging study of firstepisode patients. Arch Gen Psychiatry 2000; 57:692-699.

-35 Price CJ, Crinion J: The latest on functional imaging studies of aphasic stroke. Curr Opin Neurol 2005; 18:429-434.

\36 Cao Y, Vikingstad EM, George KP, Johnson AF, Welch KM: Cortical language activation in stroke patients recovering from aphasia with functional MRI. Stroke 1999;30:23312340 .

37 Andoh J, Martinot JL: Interhemispheric compensation: a hypothesis of TMS-induced effects on language-related areas. Eur Psychiatry 2008;23:281-288.

-38 Horn H, Federspiel A, Wirth M, Muller TJ, Wiest R, Wang JJ, Strik W: Structural and metabolic changes in language areas linked to formal thought disorder. Br J Psychiatry 2009;194:130-138.

-39 Strik WK, Dierks T, Franzek E, Stober G, Maurer K: P300 asymmetries in schizophrenia revisited with reference-independent methods. Psychiatry Res 1994;55:153-166.
40 Shenton ME, Dickey CC, Frumin M, McCarley RW: A review of MRI findings in schizophrenia. Schizophr Res 2001;49:1-52.

41 McCarley RW, Nakamura M, Shenton ME, Salisbury DF: Combining ERP and structural MRI information in first episode schizophrenia and bipolar disorder. Clin EEG Neurosci 2008;39:57-60.

42 Angrilli A, Spironelli C, Elbert T, Crow TJ, Marano G, Stegagno L: Schizophrenia as failure of left hemispheric dominance for the phonological component of language. PLoS ONE 2009;4:e4507.

43 Mitchell RL, Crow TJ: Right hemisphere language functions and schizophrenia: the forgotten hemisphere? Brain 2005;128:963-978.

44 Paus T, Zijdenbos A, Worsley K, Collins DL, Blumenthal J, Giedd JN, Rapoport JL, Evans AC: Structural maturation of neural pathways in children and adolescents: in vivo study. Science 1999;283:1908-1911.

45 Cachia A, Paillère-Martinot ML, Galinowski A, Januel D, de Beaurepaire R, Bellivier F, Artiges E, Andoh J, Bartrés-Faz D, Duchesnay E, Rivière D, Plaze M, Mangin JF, Martinot JL: Cortical folding abnormalities in schizophrenia patients with resistant auditory hallucinations. Neuroimage 2008;39: 927-935.
46 Shin SE, Lee JS, Kang MH, Kim CE, Bae JN, Jung G: Segmented volumes of cerebrum and cerebellum in first episode schizophrenia with auditory hallucinations. Psychiatry Res 2005;138:33-42.

47 Bengtsson SL, Nagy Z, Skare S, Forsman L, Forssberg H, Ullen F: Extensive piano practicing has regionally specific effects on white matter development. Nat Neurosci 2005;8: 1148-1150.

48 Dickey CC, McCarley RW, Voglmaier MM, Frumin M, Niznikiewicz MA, Hirayasu Y, Fraone S, Seidman LJ, Shenton ME: Smaller left Heschl's gyrus volume in patients with schizotypal personality disorder. Am J Psychiatry 2002;159:1521-1527.

49 Penhune VB, Zatorre RJ, MacDonald JD, Evans AC: Interhemispheric anatomical differences in human primary auditory cortex: probabilistic mapping and volume measurement from magnetic resonance scans. Cereb Cortex 1996;6:661-672.

50 McCarley RW, Salisbury DF, Hirayasu Y, Yurgelun-Todd DA, Tohen M, Zarate C, Kikinis R, Jolesz FA, Shenton ME: Association between smaller left posterior superior temporal gyrus volume on magnetic resonance imaging and smaller left temporal P300 amplitude in first-episode schizophrenia. Arch Gen Psychiatry 2002;59:321-331. 